Open Access

\title{
mRNA expression of genes involved in inflammation and haemostasis in equine fibroblast-like synoviocytes following exposure to lipopolysaccharide, fibrinogen and thrombin
}

Stine Mandrup Andreassen ${ }^{1 *}$, Lise C. Berg ${ }^{2}$, Søren Saxmose Nielsen ${ }^{3}$, Annemarie T. Kristensen $^{2}$ and Stine Jacobsen ${ }^{1}$

\begin{abstract}
Background: Studies in humans have shown that haemostatic and inflammatory pathways both play important roles in the pathogenesis of joint disease. The aim of this study was to assess mRNA expression of haemostatic and inflammatory factors in cultured equine fibroblast-like synoviocytes exposed to lipopolysaccharide (LPS), fibrinogen and thrombin. Synovial membranes were collected from metacarpo-phalangeal joints of 6 skeletally mature horses euthanized for non-orthopaedic reasons. Passage 4 fibroblast-like synoviocytes were left non-treated or treated with either $0.1 \mathrm{\mu g} / \mathrm{ml} \mathrm{LPS}, 5 \mathrm{mg} / \mathrm{ml}$ fibrinogen or $5 \mathrm{U} / \mathrm{ml}$ thrombin and harvested at time points $0,6,24$ and $48 \mathrm{~h}$. mRNA expression of serum amyloid A (SAA), interleukin-6 (IL-6), monocyte chemotactic protein 1 (MCP-1), tissue factor (TF), plasminogen activator inhibitor 1 (PAI-1), urokinase plasminogen activator (UPA), vascular endothelial growth factor (VEGF) and protease activator receptor 1 (PAR-1) was assessed using quantitative real time reverse transcriptase PCR.
\end{abstract}

Results: LPS caused a significant increase in mRNA expression of SAA, IL-6, MCP-1 and UPA, and a decrease in TF, PAI-1 and PAR-1 when compared to non-treated cells. Treatment with thrombin resulted in increased mRNA expression of SAA, IL-6, MCP-1 and PAI-1, and a decreased PAR-1 expression compared to non-treated cells. The fibrinogen-treated synoviocytes showed significantly increased mRNA expression of IL-6, MCP-1, TF and PAI-1, and decreased PAR-1 expression compared to non-treated cells.

Conclusion: LPS, fibrinogen and thrombin induced an increased gene expression of inflammatory markers in isolated equine fibroblast-like synoviocytes. LPS caused changes in gene expression promoting increased fibrinolysis, while fibrinogen and thrombin changed the gene expression resulting potentially in reduced fibrinolysis. Overall, it appeared that both inflammatory and haemostatic stimuli affected expression of genes involved in inflammatory and haemostatic pathways, supporting their importance in equine joint diseases.

Keywords: Equine, Fibroblast-like synoviocytes, Fibrinogen, Lipopolysaccharide, Thrombin, mRNA expression, Inflammation, Coagulation, Fibrinolysis, Haemostasis

\footnotetext{
*Correspondence: andreassenstine@hotmail.com

'Department of Large Animal Sciences, Medicine and Surgery group,

University of Copenhagen, Højbakkegård allé 5, DK-2630 Tåstrup, Denmark

Full list of author information is available at the end of the article
} 


\section{Background}

Joint diseases such as osteoarthritis (OA), osteochondrosis dissecans and septic arthritis affect horses regularly and are common causes of lameness and reduced performance [1-3]. The pathogenesis of joint disease is complex, but an inflammatory reaction is a common characteristic and has been studied extensively in the horse [4-6]. Increased levels of inflammatory components such as leukocytes, serum amyloid A (SAA), interleukin (IL)-1 $\beta$, IL-6, tumour necrosis factor $\alpha$ (TNF- $\alpha$ ), and matrix metalloproteinases have been demonstrated in horses with naturally occurring and experimentally induced septic arthritis and OA [4, 7-9]. Fibroblast-like synoviocytes are known to contribute to progression of joint disease [10], and in the pathogenesis of $\mathrm{OA}$ it is recognised that fibroblast-like synoviocytes participate by producing proinflammatory cytokines and cartilage-degrading mediators [11-13]. Equine septic arthritis and rheumatoid arthritis (RA) in humans are both characterized as severe inflammatory conditions showing similar pathologic occurrences such as intra-articular cell recruitment and synoviocyte driven cytokine release $[4,6,14-16]$.

Recent research in human joint disease has indicated that haemostatic pathways also play an important part in the pathogenesis of joint disease, and that activation of inflammation and haemostasis are closely related [17]. Haemostatic components are not only present in the initial stages of an intra-articular inflammatory event, it also seems that the two systems interact throughout the disease process [18]. Studies in humans and rodents have shown that both coagulation and fibrinolysis are activated intra-articularly in RA and OA $[15,19]$.

To our knowledge the potential co-occurrence of intra-articular expression of inflammatory and haemostasis markers in the horse has not previously been investigated. Lipopolysaccharide (LPS) has been described to elicit both in vivo and in vitro arthritic inflammatory responses $[7,16,20]$. Thrombin, a key proteinase in the process of fibrin formation, has been reported to be elevated in synovial fluid from humans with OA and RA [21], and when synoviocytes derived from patients with RA were exposed to thrombin, their production of IL-6 increased [14, 22]. Fibrinogen, a large coagulant protein synthesized by hepatocytes and normally absent or present in very low concentration in non-diseased synovial fluid, has been detected in elevated concentrations in synovial fluid from human OA patients [23]. In human synovial fibroblasts and pancreatic stellate cells fibrinogen has been found to induce inflammatory reactions [24, 25]. Fibrin(ogen) may regulate progression of inflammation in joint disease and has the potential to maintain inflammation $[18,24]$. It has been reported that fibrinolysis is needed to resolve joint inflammation [15]. Fibrin aggregates were found in synovial fluid in rabbits within $24 \mathrm{~h}$ of antigen-induced arthritis [26], and in horses recently published papers have shown for the first time that d-dimer, an end-product of fibrinolysis, is present in increased concentrations in synovial fluid in joint disease [27, 28]. This indicates that, along with inflammation, haemostasis is activated and may play a role in the pathogenesis of joint disease in horses and other species.

The overall aim of this study was to further our understanding of the events taking place in the early stages of joint disease by studying effects of inflammatory and haemostatic stimuli on gene expression in cultured fibroblast-like synoviocytes. The specific objectives were to investigate the effects of LPS, fibrinogen and thrombin on the expression of genes representing acute inflammation (IL-6, SAA, monocyte chemotactic protein-1 [MCP-1]), initiation of haemostasis (tissue factor [TF]), fibrinolysis (urokinase plasminogen activator [uPA], plasminogen activator inhibitor-1 [PAI-1]), angiogenesis (vascular endothelial growth factor [VEGF]) and thrombin-binding receptor (proteinase activated receptor-1 [PAR-1]) in equine fibroblast-like synoviocytes.

\section{Results}

Cell morphology became increasingly more uniform across passages. In the first passage, round and amorphous cells without pseudopods-resembling macrophage-like synoviocytes (type A cells)-were occasionally observed. In the third and fourth passage, cells were homogenous and had large pseudopods, characteristics of fibroblast-like synoviocytes (type B cells) $[29,30]$. After thawing and at every passage cell viability was assessed to $>95 \%$ (data not shown). Following, results are described according to treatments, and shown in figures according to outcome parameter (Figs. 1, 2, and 3: acute inflammation (SAA, IL-6, MCP-1); Fig. 4: initiation of haemostasis (TF); Figs. 5 and 6: fibrinolysis (uPA, PAI-1); Fig. 7: angiogenesis (VEGF) and Fig. 8: thrombin-binding receptor (PAR-1)).

\section{Non-treated synoviocytes}

For the non-treated synoviocytes there were no statistically significant changes in expression of IL-6, PAI-1 and uPA over time (Figs. 2, 5, 6). The expression of VEGF and PAR1 increased significantly over time with expression levels at every time point being significantly higher than expression levels at $0 \mathrm{~h}$ (Figs. 7 and 8). Expression levels of SAA, MCP-1 and TF were significantly higher than expression levels at $0 \mathrm{~h}$ on one or two time points (SAA: $6 \mathrm{~h}, \mathrm{MCP}-1$ : $24 \mathrm{~h}, \mathrm{TF}: 24$ and 48 h) (Figs. 1, 3 and 4).

\section{Treatment with LPS}

In synoviocytes treated with LPS mRNA expression of SAA, IL- 6 and MCP-1 was significantly higher than expression at $0 \mathrm{~h}$ at every time point $(6,24$, and $48 \mathrm{~h})$. Also, their expression levels were significantly higher than expression 


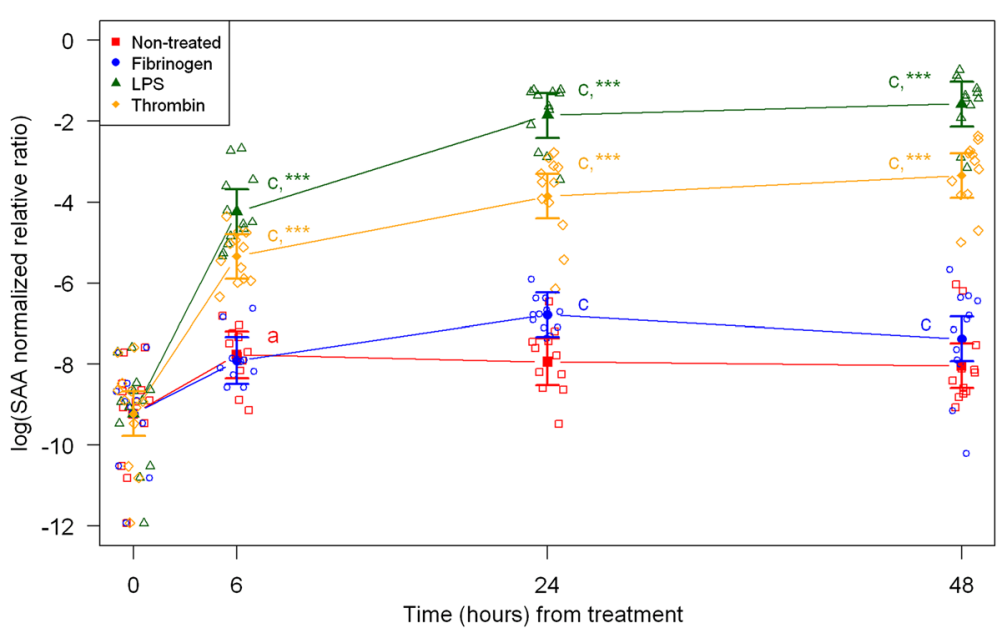

Fig. 1 mRNA expression levels of serum amyloid A (SAA) from equine fibroblast-like synoviocytes shown as log-transformed GAPDH-normalized relative ratios. Error bars show SE centered on the mean. Raw data are plotted with open symbols. Asterisks designate significant difference from non-treated within a time point $\left({ }^{*}=p<0.05 ;{ }^{* *}=p<0.01\right.$ and $\left.{ }^{* * *}=p<0.001\right)$. Superscript letters designate significant differences from time point 0 within a treatment $(a=p<0.05 ; b=p<0.01$ and $c=p<0.001)$. Treatments of the equine synovial fibroblast are coloured (Non-treated = red; fibrinogen = blue; LPS = green; thrombin = orange)

levels in the corresponding non-treated control at every time point (Figs. 1, 2 and 3). Expression of VEGF showed statistically significant increases over time compared to time point 0 , but no differences were detected between the LPS stimulated synoviocytes and the non-treated controls (Fig. 7). Expression of TF, PAI-1 and uPA showed intermittent significant increases relative to $0 \mathrm{~h}$ after LPS treatment (Figs. 4, and 6). TF, PAI-1 and PAR-1 mRNA expression levels were significantly lower than expression levels in the corresponding non-treated control at 24 and/or $48 \mathrm{~h}$ in response to LPS treatment (Figs. 4, 5 and 8). uPA mRNA expression levels increased significantly at $6 \mathrm{~h}$ after treatment compared to non-treated control (Fig. 6).

\section{Treatment with fibrinogen}

In fibrinogen-treated synoviocytes, mRNA expression of SAA increased significantly over time, but expression levels were not significantly different from the corresponding non-treated control (Fig. 1). mRNA expression of IL-6, MCP-1, TF and PAI-1 in fibrinogen treated synoviocytes was significantly increased at one or more time points relative to $0 \mathrm{~h}$, and their mRNA expression

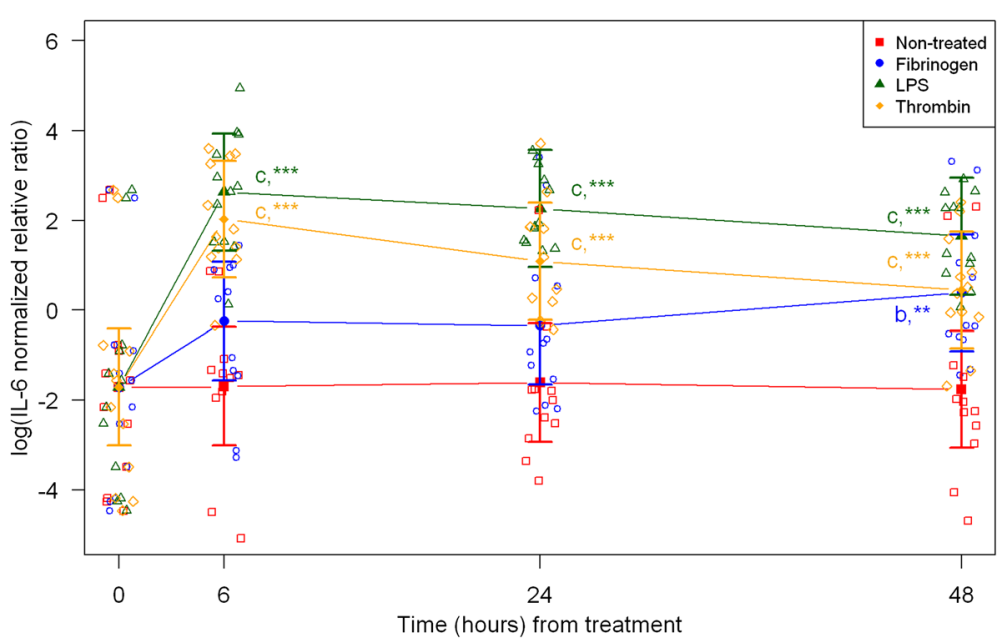

Fig. 2 mRNA expression levels of interleukin-6 (IL-6) from equine fibroblast-like synoviocytes shown as log-transformed GAPDH-normalized relative ratios. Error bars show SE centered on the mean. Raw data are plotted with open symbols. Asterisks designate significant difference from non-treated within a time point $\left({ }^{*}=p<0.05 ;{ }^{* *}=p<0.01\right.$ and $\left.{ }^{* * *}=p<0.001\right)$. Superscript letters designate significant differences from time point 0 within a treatment $(a=p<0.05 ; b=p<0.01$ and $c=p<0.001)$. Treatments of the equine synovial fibroblast are coloured (Non-treated = red; fibrinogen = blue; LPS = green; thrombin $=$ orange) 


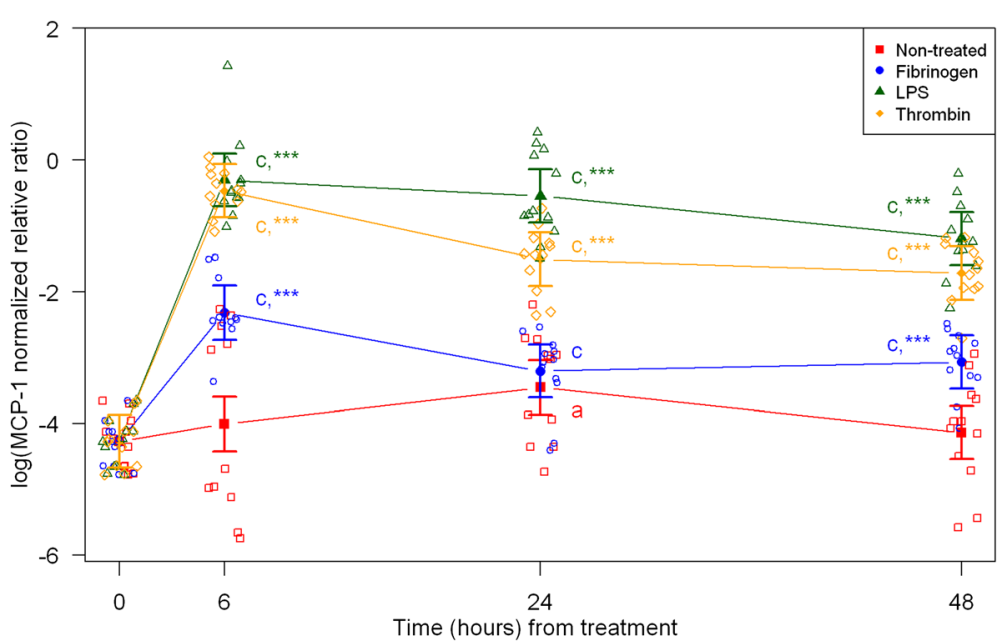

Fig. 3 mRNA expression levels of monocyte chemotactic protein-1 (MCP-1) from equine fibroblast-like synoviocytes shown as log-transformed GAPDH-normalized relative ratios. Error bars show SE centered on the mean. Raw data are plotted with open symbols. Asterisks designate significant difference from non-treated within a time point $\left(^{*}=p<0.05 ;{ }^{* *}=p<0.01\right.$ and $\left.{ }^{* * *}=p<0.001\right)$. Superscript letters designate significant differences from time point 0 within a treatment $(a=p<0.05 ; b=p<0.01$ and $c=p<0.001)$. Treatments of the equine synovial fibroblast are coloured (Non-treated = red; fibrinogen = blue; LPS = green; thrombin = orange)

levels were significantly higher than the corresponding non-treated control at one or two time points after treatment (IL-6: $48 \mathrm{~h}, \mathrm{MCP}-1: 6$ and $48 \mathrm{~h}$, TF: $6 \mathrm{~h}$ and PAI-1: 24 h; Figs. 2, 3, 4 and 5). mRNA expression of uPA, VEGF and PAR-1 did not change significantly in response to the fibrinogen treatment compared to nontreated control. VEGF and PAR-1 did show significant increases compared to time point 0 at two or three time points (Figs. 6, 7 and 8).

\section{Treatment with thrombin}

Thrombin treatment of equine synoviocytes resulted in significantly higher mRNA expression of SAA, IL-6 and MCP-1 compared to non-treated controls and to expression at $0 \mathrm{~h}$ at every time point $(6,24$ and $48 \mathrm{~h}$; Figs. 1, 2 and 3). mRNA expression of PAI-1 was significantly increased at $6 \mathrm{~h}$ after thrombin treatment compared to non-treated controls (Fig. 5). mRNA expression of PAR-1 was significantly decreased at 24 and $48 \mathrm{~h}$ after treatment

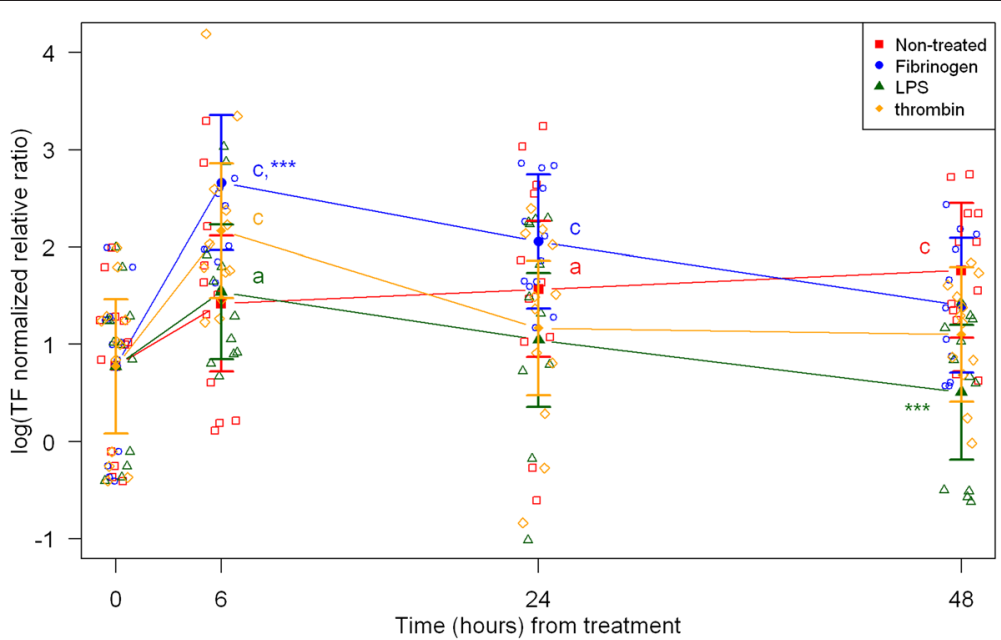

Fig. 4 mRNA expression levels of tissue factor (TF) from equine fibroblast-like synoviocytes shown as log-transformed GAPDH-normalized relative ratios. Error bars show SE centered on the mean. Raw data are plotted with open symbols. Asterisks designate significant difference from non-treated within a time point $\left({ }^{*}=p<0.05 ;{ }^{* *}=p<0.01\right.$ and $\left.{ }^{* *}=p<0.001\right)$. Superscript letters designate significant differences from time point 0 within a treatment $(a=p<0.05 ; b=p<0.01$ and $c=p<0.001)$. Treatments of the equine synovial fibroblast are coloured (Non-treated = red; fibrinogen = blue; LPS = green; thrombin $=$ orange) 


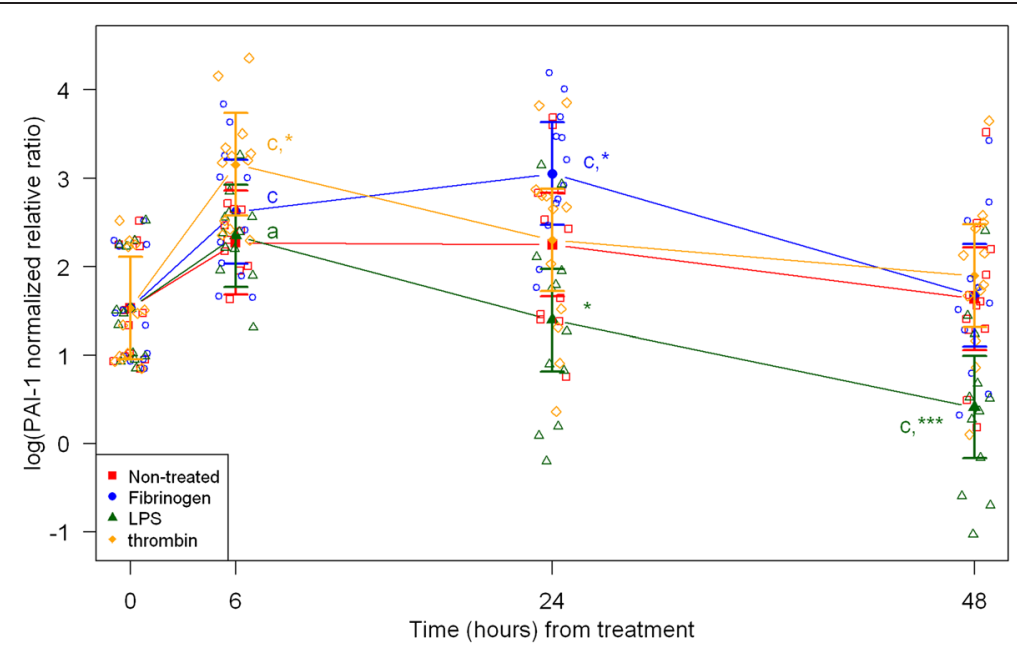

Fig. 5 mRNA expression levels of plasminogen activator inhibitor-1 (PAl-1) from equine fibroblast-like synoviocytes shown as log-transformed GAPDH-normalized relative ratios. Error bars show SE centered on the mean. Raw data are plotted with open symbols. Asterisks designate significant difference from non-treated within a time point $\left(^{*}=p<0.05 ;{ }^{* *}=p<0.01\right.$ and $\left.{ }^{* *}=p<0.001\right)$. Superscript letters designate significant differences from time point 0 within a treatment $(a=p<0.05 ; b=p<0.01$ and $c=p<0.001)$. Treatments of the equine synovial fibroblast are coloured (Non-treated $=$ red; fibrinogen = blue; LPS = green; thrombin = orange)

compared to non-treated controls (Fig. 8). At $6 \mathrm{~h}$ after thrombin treatment mRNA expression of TF, PAI-1, uPA, VEGF and PAR-1 were significantly increased compared to time point 0 (Figs. 4, 5 and 8 ).

\section{Discussion}

The results of the study showed that LPS exerted its well-described proinflammatory effects [31] in isolated equine synoviocytes by increasing expression of SAA, IL-6 and MCP-1. Moreover, LPS induced alteration of expression of factors affecting the fibrinolytic potential of the synoviocytes (up-regulation of uPA and downregulating PAI-1) and caused a decrease in mRNA expression of TF. Thrombin treatment also induced inflammatory changes by increased expression of SAA, IL-6 and MCP-1, but decreased fibrinolysis by an early increase in PAI-1. Fibrinogen exposure also caused an increase in expression of inflammatory markers (IL-6 and MCP-1). In contrast to LPS, fibrinogen induced increased mRNA expression of TF and PAI-1 in the synoviocytes-changes that have

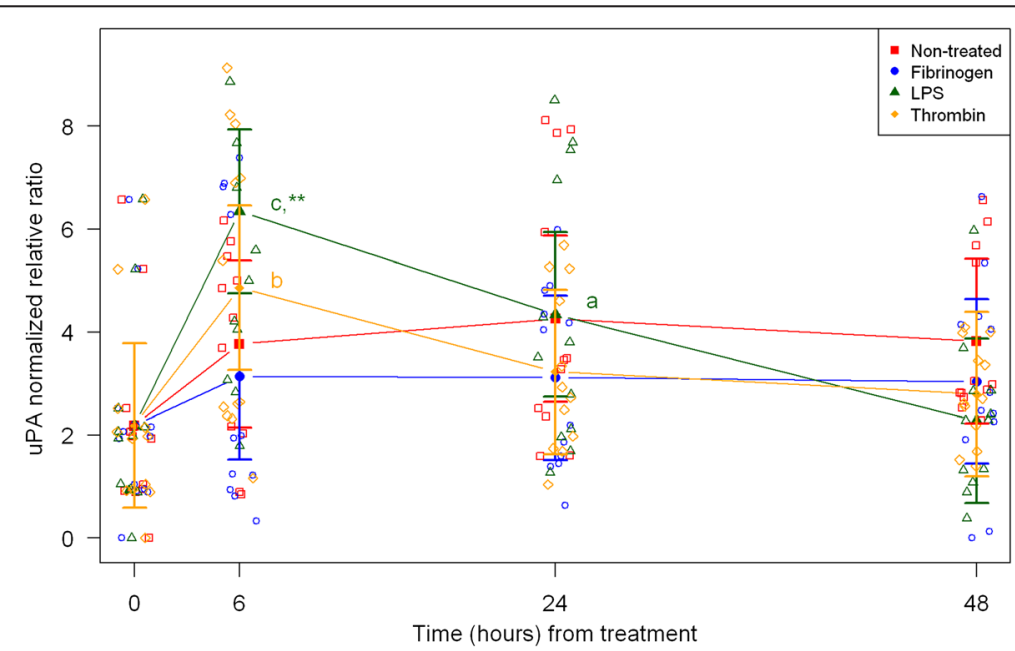

Fig. 6 mRNA expression levels of urokinase plasminogen activator (UPA) from equine fibroblast-like synoviocytes shown as GAPDH-normalized relative ratios. Error bars show SE centered on the mean. Raw data are plotted with open symbols. Asterisks designate significant difference from non-treated within a time point $\left({ }^{*}=p<0.05 ;{ }^{* *}=p<0.01\right.$ and $\left.{ }^{* * *}=p<0.001\right)$. Superscript letters designate significant differences from time point 0 within a treatment $(a=p<0.05 ; b=p<0.01$ and $c=p<0.001)$. Treatments of the equine synovial fibroblast are coloured (Non-treated = red; fibrinogen = blue; LPS = green; thrombin = orange) 


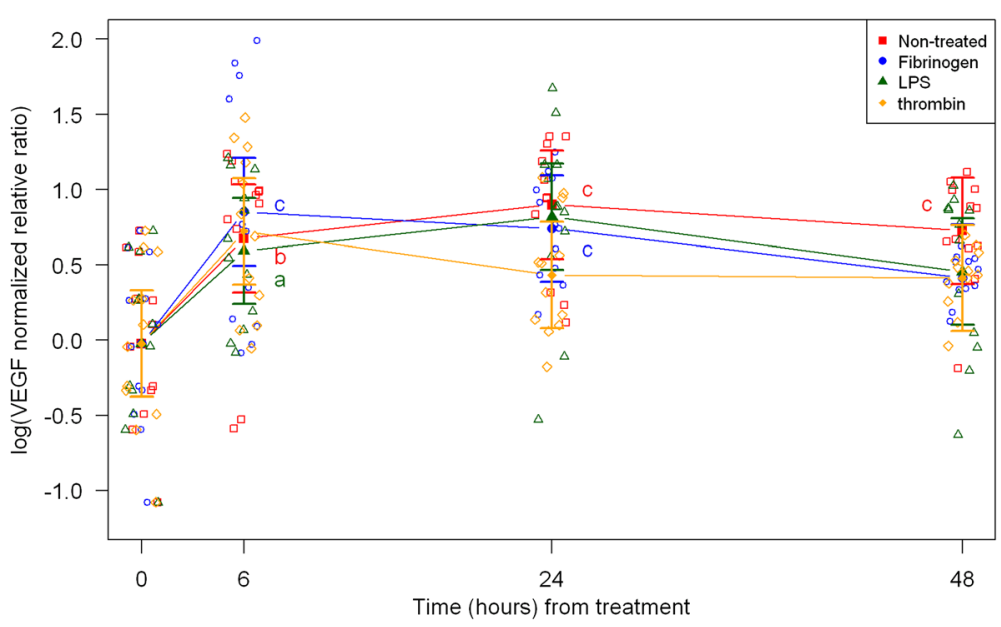

Fig. 7 mRNA expression levels of vascular endothelial growth factor (VEGF) from equine fibroblast-like synoviocytes shown as log-transformed GAPDH-normalized relative ratios. Error bars show SE centered on the mean. Raw data are plotted with open symbols. Asterisks designate significant difference from non-treated within a time point $\left(^{*}=p<0.05 ;{ }^{* *}=p<0.01\right.$ and $\left.{ }^{* * *}=p<0.001\right)$. Superscript letters designate significant differences from time point 0 within a treatment $(a=p<0.05 ; b=p<0.01$ and $c=p<0.001)$. Treatments of the equine synovial fibroblast are coloured (Non-treated $=$ red; fibrinogen = blue; $\mathrm{LPS}=$ green; thrombin = orange)

the potential to increase extravascular coagulation (TF) and inhibit fibrinolysis (PAI-1). All three treatments decreased the mRNA expression of PAR-1.

A common characteristic of several joint conditions is inflammation, and studies have shown its importance in development and healing of disease processes $[15,17,18]$. Lately haemostatic reactions have obtained interest, since upregulation of factors involved in coagulation and fibrinolytic pathways has been shown to occur intraarticularly in mice with antigen-induced arthritis [19] and in humans with naturally occurring arthritis $[15,23]$. It thus seems, just as in systemic reactions, that both inflammatory and haemostatic pathways are activated and likely interlinked in the joint cavity $[17,18]$. One link between inflammation and haemostasis is fibrinogen, which is an acute phase protein upregulated during inflammation, but also serves a crucial role in haemostasis. Fibrinogen has been shown to serve as inducer and regulator of inflammatory reactions in joint diseases in humans and rodents $[17,18,24,32]$. Thrombin is another link between inflammation and haemostasis. While thrombin has traditionally been thought of as a procoagulant through its induction

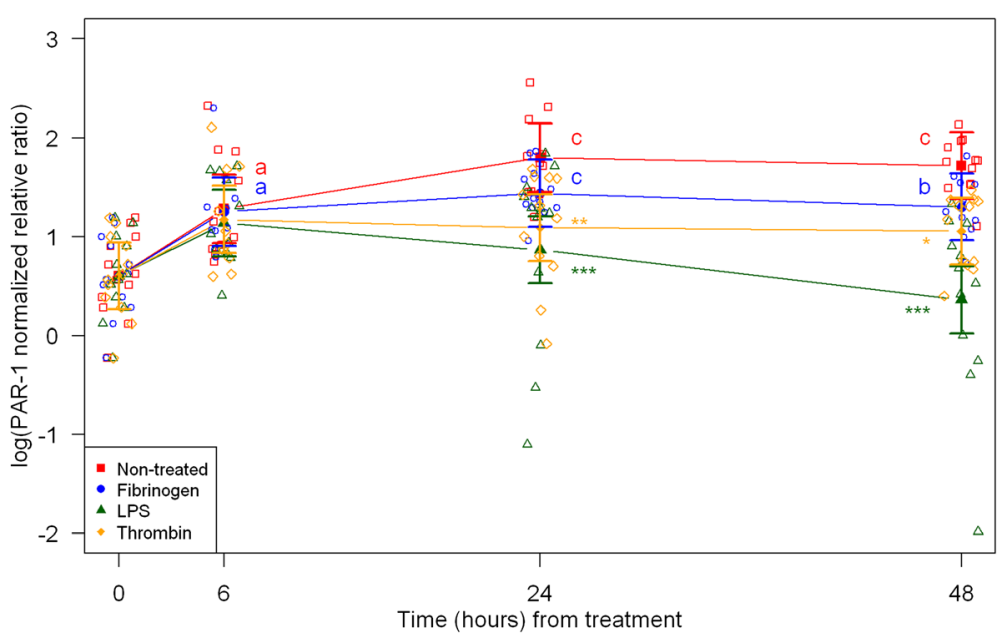

Fig. 8 mRNA expression levels of proteinase activated receptor 1 (PAR-1) from equine fibroblast-like synoviocytes shown as square root-transformed GAPDH-normalized relative ratios. Error bars show SE centered on the mean. Raw data are plotted with open symbols. Asterisks designate significant difference from non-treated within a time point $\left(^{*}=p<0.05 ;{ }^{* *}=p<0.01\right.$ and $\left.{ }^{* * *}=p<0.001\right)$. Superscript letters designate significant differences from time point 0 within a treatment $(a=p<0.05 ; b=p<0.01$ and $c=p<0.001)$. Treatments of the equine synovial fibroblast are coloured (Non-treated = red; fibrinogen = blue; LPS = green; thrombin = orange) 
of fibrin formation, it has also been shown to be a potent inducer of production of inflammatory biomolecules such as MCP-1 and IL-6 and activator of leukocytes [14, 33]. In horses, inflammatory changes in joints with spontaneous or experimentally-induced arthritis are well-described [20, 34, 35]. In contrast, only few studies have attempted to assess haemostatic factors intra-articularly in horses. Two recent studies have described increases in d-dimer in synovial fluid of horses with joint disease [28,36], indicating that fibrinolysis is active in the intra-articular compartment of horses with joint inflammation. It is thus possible that the cross-talk between inflammation and haemostasis suggested as a hallmark of human joint disease [37, 38] may also be at play in horses.

LPS is a well-known inflammatory inducer, and it was therefore not surprising that it caused an up-regulation of mRNA expression of the inflammatory markers SAA and IL- 6 starting at $6 \mathrm{~h}$ and continuing till the end of the study $(48 \mathrm{~h})$. Similar results have been found in other in vitro studies showing LPS-induced increases in SAA mRNA expression in chicken synovial fibroblast [30] and in IL-6 mRNA expression in equine and human synoviocytes $[14,16]$. LPS exposure also caused the equine synoviocytes to express MCP-1 mRNA. While this to our knowledge is the first time that MCP-1 is described in horses, similar results have been found in IL-1 $\beta$-treated human synoviocytes [39] and in mice with haemophilic synovitis [40]. MCP-1 serves to recruit mononuclear cells to the joint compartment [39-41], and MCP-1 has been suggested to correlate with the degree of inflammatory changes in human synovial membrane [42].

Thrombin stimulation caused significant increases in mRNA expressions of the three inflammatory markers of this study (SAA, IL-6 and MCP-1) in the synoviocytes, resembling the response observed after LPS stimulation. Thrombin-induced IL-6 production has previously been shown in human synovial fibroblasts [14], and MCP-1 induction by thrombin has been shown in endothelial cells [43] and MCP-1 was found elevated in synovial fluid from haemophilic mice [40]. Proinflammatory effects of thrombin have thus been demonstrated across species and tissues.

The inflammation-inducing potential of fibrinogen is less well described than that of LPS. In the present study, fibrinogen induced a significant increase in mRNA expression of IL- 6 and MCP- 1 after 48 and $6 \mathrm{~h}$ of stimulation, respectively. In species other than the horse, fibrinogen exposure has been described to cause inflammatory changes: increased IL- 6 concentrations were found in culture supernatant from fibrinogen-treated human pancreatic stellate cells [25], and fibrinogen induced increases in MCP-1 expression was shown in endothelial cells of humans and pigs $[44,45]$. In articular tissue, fibrinogen exposure has been shown to exert proinflammatory functions. Human synovial fibroblasts cultured in vitro in the presence of fibrinogen had increased expression of intercellular adhesion molecules (ICAM) and interleukin-8 (IL-8) [24]. By increasing expression of ICAM, IL-8, and MCP-1 fibrinogen may serve to attract and retain leukocytes intra-articularly, but at this stage the exact effects of fibrinogen in the intraarticular compartment are unknown.

Factors involved in haemostasis pathways were induced in equine synoviocytes after LPS, thrombin and fibrinogen exposure. Fibrinogen-treated synoviocytes showed increased mRNA expression of TF at $6 \mathrm{~h}$ and thereafter a gradual decline. In contrast, LPS-treatment decreased the mRNA expression of TF at $48 \mathrm{~h}$. This is surprising and interesting, since LPS stimulation has been found to increase TF in equine peritoneal macrophages [46]. In vivo, a gradual increase in TF mRNA expression over 7 days has been demonstrated in mice with antigeninduced arthritis [19] and increased TF activities along with increased fibrinogen concentrations have been found in inflamed synovial fluid from human arthritis [23]. TF initiates cell based haemostasis [47] resulting in thrombin formation [48], but TF is also described as a link between inflammation and haemostasis [23]. TF has been suggested to play an active role in attraction of monocytes to the synovial membrane [49], and a significant correlation between synovial fluid TF concentrations and leukocyte counts has been demonstrated [15]. To further characterize and understand the synovial TF response in horses, the in vitro results presented here need to be corroborated by in vivo data.

The balance between UPA and PAI-1 determines the fibrinolytic activity in the joint $[50,51]$. The LPS-treated equine synoviocytes in this study showed a significant increase in uPA mRNA expression at $6 \mathrm{~h}$ followed by a steady decline, and a gradual decrease in PAI-1 mRNA expression throughout the 48 -h study period, which would increase fibrinolysis. In contrast, fibrinogen- and thrombin-treated synoviocytes did not show changes in uPA mRNA expression, while mRNA expression of PAI-1 increased significantly at 24 and $6 \mathrm{~h}$, respectively. Taken together, this suggests that an inflammatory stimulus increases the fibrinolytic capacity of equine synoviocytes first by an UPA increase and then a PAI-1 decrease, whereas the haemostatic proteins fibrinogen and thrombin appear to inhibit the fibrinolytic capacity of equine synoviocytes by upregulation of PAI-1. In human synovial tissue obtained from patients with OA and RA both UPA and $3 \mathrm{~B} 2$ thyc $=10$ ? $>$ PAI-1 mRNA expression was increased [32], and in mice with antigen-induce arthritis uPA mRNA expression in synovial tissue quickly increased and peaked around $4 \mathrm{~h}$, while PAI- 1 was increased in the first 3 days after induction of arthritis [19]. These findings seemingly suggest that inflamed joints develop a pro- or hyper-coagulable state with tendency to produce and clot 
more fibrinogen [19]. If the same is true for the horse, the results of this study indicate that fibrinolytic pathways are intact in initial inflammatory arthritis, and when fibrinogen and thrombin accumulation occurs in the joint cavity, coagulation increases and fibrinolysis decreases, making the joint potentially vulnerable to fibrin deposition and its deleterious effects.

PAR-1, a trans-membrane receptor for thrombin and other proteinases [52], showed significantly lower expression at 24 and $48 \mathrm{~h}$ after all three treatments compared to the non-treated controls. LPS caused the most downregulation of PAR-1 expression. PAR-1 knockout mice have shown less clinical symptoms in antigen-induced arthritis compared to wild type mice [53], and PAR-1 has also been demonstrated in human RA synovial fibroblasts $[54,55]$. These results indicate that PAR- 1 plays a role in joint disease processes [22]. Increased synovial fibroblast proliferation [54] and increased mRNA expression in synovial fibroblast of inflammatory cytokines IL-6, IL-8 and TNF- $\alpha$ have been shown to be mediated through PAR-1 $[14,56]$. Whether inflammation up- or down-regulates expression of PAR-1 in articular tissues is not currently clear. Opposite to our results, PAR-1 has been found in increased levels in inflamed human muscle cells [57] and infected murine smooth muscle cell [58], and thrombin and LPS have been shown to induce PAR-1 mRNA expression in endothelial cells [59] and in rat astrocytes [60]. In accordance with the findings of our study, decreasing levels of PAR-1 mRNA has been found in ischemic rat brain [61] and after TNF- $\alpha$ stimulation of human endothelial cells [62]. Decreased PAR-1 expression in response to inflammatory and haemostatic stimuli might indicate a down-regulation of inflammatory pathways in equine synovial fibroblasts.

VEGF was the only marker investigated, whose expression pattern was not changed in response to any of the treatments. VEGF was initially expected to show increased expression pattern in the stimulated synoviocytes, as it has been demonstrated to have an angiogenic role in inflammatory joint diseases [63] and has been found in increased concentrations in synovial fluid of human OA and RA patients [21, 64]. The angiogenic effects and pro-inflammatory properties of VEGF in synovial inflammation can potentially lead to hyperplasia of the synovial membrane, pannus formation and development of osteoarthritis $[65,66]$. Several cell types such as rat lung pericytes, human pancreatic stellate cells, human fibroblast, human and bovine endothelial cells have shown up-regulation of VEGF mRNA after LPS, thrombin or fibrinogen treatment [25, 67-69]. While studies in humans demonstrated increased VEGF concentrations in synovial fluid from RA patients [21, 64], a study by Salvi et al. [19] detected no change in VEGF expression in synovial tissue from antigen-induced arthritis in mice. Whether
VEGF is consistently up-regulated in joint inflammation is thus not clear at this stage and warrants further study.

This is the first study evaluating the relationship between inflammation and haemostasis in equine fibroblast-like synoviocytes. Obviously, the single cell type with exposure to one inducing factor at a time cannot reflect the complexity of events taking place in an inflamed joint, and further studies are warranted before firm conclusions regarding the interplay between inflammatory and haemostatic pathways in equine joint disease may be drawn. However, the findings of our study help elucidate specific interactions between individual reactants, which are otherwise impossible to tease out of the complex microenvironment of the diseased joint.

In the present study, passage- 4 equine synovial fibroblasts were used. It is well documented that at this passage the cell population is homogenous, because the culture environment does not favour the macrophage-like synoviocytes $[29,30]$. It is clear from the results of the present study that it is important to include non-treated cell cultures at all investigated time points to control for culture-induced effects on mRNA expression of the chosen markers unrelated to the tested treatments. The non-treated cultures showed significant increases in mRNA expression of SAA, MCP-1, TF, VEGF and PAR-1 over time, showing that the culture environment affected the synoviocytes.

\section{Conclusion}

In conclusion, the results of this study indicate that in equine fibroblast-like synoviocytes, inflammatory and haemostatic pathways are at play simultaneously and affect each other. All three treatments (LPS, fibrinogen and thrombin) increased gene expression of inflammatory markers. LPS treatment supported fibrinolysis, in contrast fibrinogen and thrombin decreased fibrinolytic potential of the fibroblast-like synoviocytes at mRNA level. Initiation of haemostasis in synoviocytes was affected in opposing directions by LPS and fibrinogen, shown as decreased and increased gene expression of TF, respectively. The perspectives of these findings are a deeper understanding of events taking place in an inflamed joint. Further studies with a closer clinical application are highly needed to elucidate whether haemostasis plays a role in equine joint inflammation corresponding to the current understanding of human joint disease.

\section{Methods}

\section{Sample population}

Synovial membranes were collected from the dorsal and palmar joint recesses of both metacarpo-phalangeal joints of six skeletally mature (10 - 13 years old) horses of different breeds euthanized for non-orthopaedic reasons at the department of Veterinary Clinical and Animal Science, University of Copenhagen according to regulations of Danish law. Samples were harvested aseptically within 
$1 \mathrm{~h}$ of euthanasia. The joints were macroscopically normal and synovial fluid appeared normal in quantity, viscosity and colour. Synovial tissue was pooled from both metacarpo-phalangeal joints of the same horse.

\section{Isolation and culture of equine fibroblast-like synoviocytes}

Synoviocytes were isolated from the synovial tissue by enzymatic digestion $(1 \mathrm{mg} / \mathrm{ml}$ collagenase type 1 (Invitrogen $^{\mathrm{TM}}$, Life Technologies, Nærum, Denmark), $1 \%$ penicillin/streptomycin (Invitrogen ${ }^{\mathrm{TM}}$ ), 1 \% gentamycin (Invitrogen $^{\mathrm{TM}}$ ) in Dulbecco's Modified Eagle Medium (DMEM) High Glucose (Invitrogen ${ }^{\mathrm{TM}}$ ) for $3 \mathrm{~h}$ at $37^{\circ} \mathrm{C} /$ $30 \mathrm{rpm}$. The released synoviocytes were centrifuged at $450 \mathrm{x} \mathrm{g}$ for $5 \mathrm{~min}$, washed twice in sterile phosphate buffered saline and cryopreserved with $10 \%$ dimethyl sulfoxide in foetal calf serum in liquid nitrogen until study start.

The culture medium consisted of DMEM with addition of $10 \%$ foetal calf serum (Invitrogen ${ }^{\mathrm{TM}}$ ), $5 \mathrm{ml}$ penicillin $(100 \mathrm{IU} / \mathrm{ml}) /$ streptomycin $(100 \mu \mathrm{g} / \mathrm{ml})$, and $2.5 \mathrm{ml}$ gentamycin $(10 \mu \mathrm{g} / \mathrm{ml})$.

At study start, the synoviocytes were thawed rapidly at $37{ }^{\circ} \mathrm{C}$. After equalizing the cryopreserved synoviocytes with culture medium, synoviocytes were rinsed twice with culture medium to remove dimethyl sulfoxide remnants.
Cells were seeded in monolayer cultures and cultured at $37{ }^{\circ} \mathrm{C} / 5 \% \mathrm{CO}_{2}$ in a humidified atmosphere (passage 1 ). Culture medium was aspirated after 24 h to remove nonadherent synoviocytes. Culture medium was subsequently changed every 48 to $72 \mathrm{~h}$ until synoviocytes reached confluence, and upon confluence the synoviocytes were passaged using $0.25 \%$ trypsin/1 mM EDTA (Invitrogen ${ }^{\mathrm{TM}}$ ). Passage-4 synoviocytes were transferred to 24-well culture plates at a density of 250,000 cells/well. Twenty-four hours prior to stimulation the culture conditions were changed to serum-free.

\section{Experimental design}

Initial experiments were conducted to establish concentration and incubation time for the three stimulants: LPS from Escherichia coli strain 055:B5 (\# L2880, Sigma-Aldrich Denmark ApS), plasminogen-depleted fibrinogen (\# 341578, Calbiochem, Merck, Darmstadt, Germany) and thrombin (\# T7572, Sigma-Aldrich Denmark ApS) (data not shown). LPS was reconstituted in sterile water and mixed with serum-free medium and added directly to the wells in a concentration of $0.1 \mu \mathrm{g} / \mathrm{ml}$ as previously described [70, 71]. Fibrinogen was reconstituted in $37{ }^{\circ} \mathrm{C}$ serum-free culture medium and added directly to the wells in a concentration of $5 \mathrm{mg} / \mathrm{ml}$ as previously described $[11,25,30]$. Thrombin was

Table 1 Equine specific primers used for quantitative real-time reverse transcriptase PCR

\begin{tabular}{|c|c|c|c|}
\hline Primer & Primer sequence $\left(5^{\prime} \rightarrow 3^{\prime}\right)$ & Product & NCBI source/ \\
\hline name & Forward/reverse & size & Reference \\
\hline \multirow[t]{2}{*}{ SAA } & CCT GGG CTG CTA AAG TCA TC/ & $169 \mathrm{bp}$ & AF240364.1 \\
\hline & AGG CCA TGA GGT CTG AAG TG & & \\
\hline \multirow[t]{2}{*}{$\mathrm{IL}-6$} & ATG GCA GAA AAA GAC GGA TG/ & $220 \mathrm{bp}$ & {$[72]$} \\
\hline & GGG TCA GGG GTG GTT ACT TC & & \\
\hline \multirow[t]{2}{*}{ MCP-1 } & ATT GGC CAA GGA GAT CTG TG/ & 166 bp & EU779497.1 \\
\hline & ATA TCA GGG GGC ATT TAG GG & & \\
\hline \multirow[t]{2}{*}{ TF } & TGC ACT AGC CAA CAC AAA GC/ & $101 \mathrm{bp}$ & XM_001491449.2 \\
\hline & CAG AGA CAC AGC CAG GAT GA & & \\
\hline \multirow[t]{2}{*}{ UPA } & ATG TAT GGT GAT GCC CGT TT/ & $175 \mathrm{bp}$ & XM_001502951.3 \\
\hline & CAC AGC ATT TTG GTG GTG AC & & \\
\hline \multirow[t]{2}{*}{ PAI-1 } & AAG GGT CCG CTT CCT ACA AT/ & 204 bp & XM_001492517.3 \\
\hline & TTG AAC TGC ATT GCC TCT TG & & \\
\hline \multirow[t]{2}{*}{ VEGF } & CAA CGA CGA GGG CCT AGA GT/ & $100 \mathrm{bp}$ & [73] \\
\hline & CAT CTC TCC TAT GTG TGG CTT TG & & \\
\hline \multirow[t]{2}{*}{ PAR1 } & TTC GTG ATA AGC CTG CCT CT/ & 212 bp & XM_001503957.2 \\
\hline & GTA AAA CGC TGC AGT GAC GA & & \\
\hline \multirow[t]{2}{*}{ GAPDH } & GGG TGG AGC CAA AAG GGT CAT CAT/ & $417 \mathrm{bp}$ & {$[74]$} \\
\hline & AGC $\Pi \pi$ CTC CAG GCG GCA GGT CAG & & \\
\hline
\end{tabular}

Primers used to amplify specific genes in LPS, fibrinogen, thrombin and non-treated equine fibroblast-like synoviocytes: SAA: serum amyloid A. IL-6: interleukin-6. MCP-1: monocyte chemotactic protein-1. TF: tissue factor. UPA: urokinase plasminogen activator. PAI-1: plasminogen activator inhibitor-1. VEGF: vascular endothelial growth factor. PAR-1: protease activator receptor-1. GAPDH: gluceraldehyde-3-phosphate dehydrogenase 
reconstituted in sterile water containing $0.1 \%(\mathrm{w} / \mathrm{v})$ bovine serum albumin, mixed with serum-free culture medium and added directly to the wells in a concentration of $5 \mathrm{U} / \mathrm{ml}[14,54]$. Synoviocytes were harvested after 0,6 , 24 , and $48 \mathrm{~h}$ of stimulation. Non-treated controls were cultured in standard serum-free culture medium as described above. All experiments were performed in duplicate for each horse.

\section{RNA isolation and quantitative real time reverse transcriptase PCR analysis}

Total RNA was extracted from the synoviocytes using the Qiagen RNeasy Plus mini kit (Qiagen Nordic, Copenhagen $\varnothing$, Denmark ). Cells were first homogenized through a QIAshredder column for $2 \mathrm{~min}$ at $10,000 \mathrm{x} \mathrm{g}$, and all subsequent steps were performed as described in the manufacturer's manual. Resulting total RNA was quantified by optical density measurement (NanoDrop TM Spectrophotometer (Thermo Scientific, Wilmington, US)). Twelve randomly selected samples were run in a bioanalyzer (Agilent 2100 Bioanalyzer (Agilent Technologies, Hørsholm, Denmark)) to verify RNA quality. Total RNA isolates were kept at $-80{ }^{\circ} \mathrm{C}$ until further analysis.

cDNA was synthesized from 200 ng total RNA. The reverse transcriptase PCR mastermix (Promega Biotech AS, Nacka, Sweden) consisted of $5 \mu \mathrm{L}$ RT buffer, $1.3 \mu \mathrm{L}$ dNTP mix $(10 \mu \mathrm{M}), 0.25 \mu \mathrm{L}$ random hexamer primers $(2 \mu \mathrm{g} / \mu \mathrm{L}), 0.25 \mu \mathrm{L}$ Oligo-dT primers $(0.5 \mu \mathrm{g} / \mu \mathrm{L}), 0.8 \mu \mathrm{L}$ RNasin ${ }^{\oplus}$ Plus RNase inhibitor $(40 \mathrm{U} / \mu \mathrm{L}), 1 \mu \mathrm{L}$ M-MLV Reverse Transcriptase $(200 \mathrm{U} / \mu \mathrm{L})$ and water. Reverse transcription was performed in a BIOmetra ${ }^{\oplus} \mathrm{T}$-Gradient thermocycler (Thermo scientific, Fisher Scientific, Denmark) at $25{ }^{\circ} \mathrm{C}$ for $10 \mathrm{~min}, 42{ }^{\circ} \mathrm{C}$ for $60 \mathrm{~min}$, and $95{ }^{\circ} \mathrm{C}$ for $5 \mathrm{~min}$. Samples were stored at $-20^{\circ} \mathrm{C}$.

Species-specific intron-spanning equine primers were used to amplify SAA, IL-6, MCP-1, TF, uPA, PAI-1, VEGF and PAR-1, and products were verified by gel electrophoresis and sequencing. Primers are listed in Table 1. Quantitative real time reverse transcriptase PCR was performed in triplicates using the LightCycler ${ }^{\circledR}$ Fast Start DNA Master SYBR Green I and LightCycler ${ }^{\circledR}$ RealTime PCR System (Roche, Hvidovre, Denmark).

\section{Data analysis}

Results were calculated using the efficiency corrected calculation method also known as the Roche Applied Sciences E(efficiency)-method:

Normalized relative ratio $(\mathrm{NRR})=\mathrm{E}_{\mathrm{t}} \mathrm{CT}$ (target calibrator) CT (target sample) $/ E_{r}$ CT (reference calibrator) - CT (reference sample) [75].

All results were normalized to reference gene gluceraldehyde-3-phosphate dehydrogenase (GAPDH), selected after initial testing of three reference genes (GAPDH, $\beta$-actin and ribosomal RNA (18 S)).
mRNA expression for each of the outcome parameters was compared among treatments at the different time points using a random intercept, random slope model in $\mathrm{R}$ [76]. For each of the outcome parameters, the NRR was log-transformed to achieve residuals $(\varepsilon)$ which could be deemed independent identically distributed Normal $(0, \sigma 2)$ except for the parameter PAR-1, where a square root transformation was used and for uPA, which was not transformed at all. The general model used was thus: transformation $(\mathrm{NRR})=\alpha+\mathrm{TX}+$ time $+\mathrm{TX} \mathrm{x}$ time $+\varepsilon$.

Where transformation(NRR) was the transformed NRR for the specific outcome parameter (using the transformations stated above), TX the fixed and random effect of treatment (non-treated, fibrinogen, thrombin or LPS treated), time the fixed and random effect of time, and TX $\mathrm{x}$ time the interaction between time and TX. Statistical significance was defined as $\mathrm{p}<0.05$ for all the analyses. The results were presented as pairwise comparisons between treatments and non-treated within a time point $(6,24$ and $48 \mathrm{~h})$ and all measurements were compared to time point $0 \mathrm{~h}$.

\section{Abbreviations}

SAA: Serum amyloid A; TF: Tissue factor; uPA: Urokinase plasminogen activator; PAI-1: Plasminogen activator inhibitor-1; VEGF: Vascular endothelial growth factor; PAR-1: Protease activator receptor 1; MCP-1: Monocyte chemotactic protein-1; IL-6: Interleukin-6; IL-1 $\beta$ : Interleukin-1 $\beta$; qRT-PCR: Quantitative real time reverse transcriptase polymerase chain reaction; LPS: Lipopolysaccharide; TNF-a: Tumour necrosis factor a; NRR: Normalized relative ratio; GAPDH: Glyceraldehyde-3-phosphate dehydrogenase; DMEM: Dulbecco's Modified Eagle Medium; RNA: Ribonucleic acid; mRNA: Messenger ribonucleic acid; cDNA: Complementary deoxyribonucleic acid; EDTA: Ethylenediaminetetraacetic acid; OA: Osteoarthritis; RA: Rheumatoid arthritis; ICAM: Intercellular adhesion molecules; IL-8: Interleukin-8.

\section{Competing interests}

The authors declare that they have no competing interests.

\section{Authors' contributions}

SMA, LCB, ATK and STJ conceived and designed the study. LCB isolated the synoviocytes, designed primers and supervised the laboratory work. SMA performed the cell culture, RNA isolation and the qRT-PCR analysis. SSN, SMA and STJ performed the statistical analysis, prepared the figures and interpreted the data. SMA prepared the manuscript. STJ, LCB, ATK and SSN revised the manuscript critically for intellectual content. All authors have read and approved the final manuscript.

\section{Authors' information}

Annemarie T. Kristensen and Stine Jacobsen: shared last authorship.

\section{Acknowledgement}

This study was supported by the Danish Horse Levy Fund and the Memorial Trust of Veterinarian H. P. Christensen. The authors wish to thank the invaluable support of PhD colleague Sanni Hansen (Faculty of Health and Medical Sciences, University of Copenhagen) for providing help in the laboratory and writing assistance.

\section{Author details}

${ }^{1}$ Department of Large Animal Sciences, Medicine and Surgery group, University of Copenhagen, Højbakkegård allé 5, DK-2630 Tåstrup, Denmark. ${ }^{2}$ Department of Veterinary Clinical and Animal Sciences, University of Copenhagen, Dyrlægevej 16, DK-1870 Frederiksberg C, Denmark. ${ }^{3}$ Department of Large Animal Sciences, University of Copenhagen, Grønnegårdsvej 8, DK-1870 Frederiksberg C, Denmark. 
Received: 23 September 2014 Accepted: 1 June 2015 Published online: 27 June 2015

\section{References}

1. Jonsson L, Roepstorff L, Egenvall A, Nasholm A, Dalin G, Philipsson J. Prevalence of clinical findings at examinations of young Swedish warmblood riding horses. Acta Vet Scand. 2013;55:34.

2. Ireland JL, Clegg PD, McGowan CM, McKane SA, Chandler KJ, Pinchbeck GL. Disease prevalence in geriatric horses in the United Kingdom: Veterinary clinical assessment of 200 cases. Equine Vet J. 2012;44:101-6.

3. Murray RC, Walters JM, Snart H, Dyson SJ, Parkin TDH. Identification of risk factors for lameness in dressage horses. Vet J. 2010;184:27-36.

4. Bertone AL, Palmer JL, Jones J. Synovial fluid cytokines and eicosanoids as markers of joint disease in horses. Vet Surg. 2001;30:528-38.

5. Mcllwraith CW. Use of synovial fluid and serum biomarkers in equine bone and joint disease: a review. Equine Vet J. 2005;37:473-82.

6. Kidd JA, Barr ARS, Tarlton JF. Use of matrix metalloproteinases 2 and 9 and white blood cell counts in monitoring the treatment and predicting the survival of horses with septic arthritis. Vet Rec. 2007;161:329-34.

7. Lindegaard C, Gleerup KB, Thomsen MH, Martinussen T, Jacobsen S, Andersen PH. Anti-inflammatory effects of intra-articular administration of morphine in horses with experimentally induced synovitis. Am J Vet Res. 2010;71:69-75

8. Ross TN, Kisiday JD, Hess T, Mcllwraith CW. Evaluation of the inflammatory response in experimentally induced synovitis in the horse: a comparison of recombinant equine interleukin 1 beta and lipopolysaccharide. Osteoarthritis Cartilage. 2012;20:1583-90.

9. Kamm JL, Nixon AJ, Witte TH. Cytokine and catabolic enzyme expression in synovium, synovial fluid and articular cartilage of naturally osteoarthritic equine carpi. Equine Vet J. 2010;42:693-9.

10. Chang SK, Gu Z, Brenner MB. Fibroblast-like synoviocytes in inflammatory arthritis pathology: the emerging role of cadherin-11. Immunol Rev. 2010;233:256-66

11. Briston L, Dudhia J, Lees P. Age-related differences in prostaglandin E(2) synthesis by equine cartilage explants and synoviocytes. J Vet Pharmaco Ther. 2010;33:268-76.

12. Del Rey MJ, Usategui A, Izquierdo E, Canete JD, Blanco FJ, Criado G, et al. Transcriptome analysis reveals specific changes in osteoarthritis synovial fibroblasts. Ann Rheum Dis. 2012;71:275-80.

13. Benito MJ, Veale DJ, FitzGerald O, van den Berg WB, Bresnihan B. Synovial tissue inflammation in early and late osteoarthritis. Ann Rheum Dis. 2005;64:1263-7.

14. Chiu YC, Fong YC, Lai CH, Hung $\mathrm{CH}$, Hsu HC, Lee TS, et al. Thrombininduced IL-6 production in human synovial fibroblasts is mediated by PAR1, phospholipase C, protein kinase C alpha, c-SrC, NF-kappa B and p300 pathway. Mol Immunol. 2008;45:1587-99.

15. So AK, Varisco PA, Kemkes-Matthes B, Herkenne-Morard C, Chobaz-Peclat V Gerster JC, et al. Arthritis is linked to local and systemic activation of coagulation and fibrinolysis pathways. J Thromb Haemost. 2003;1:2510-5.

16. Armstrong $S$, Lees $P$. Effects of carprofen ( $R$ and $S$ enantiomers and racemate) on the production of $\mathrm{LL}-1, \mathrm{IL}-6$ and TNF-alpha by equine chondrocytes and synoviocytes. J Vet Pharmacol Ther. 2002;25:145-53.

17. Busso N, Morard C, Salvi R, Peclat V, So A. Role of the tissue factor pathway in synovial inflammation. Arthritis Rheum. 2003;48:651-9.

18. Flick MJ, LaJeunesse CM, Talmage KE, Witte DP, Palumbo JS, Pinkerton MD, et al. Fibrin(ogen) exacerbates inflammatory joint disease through a mechanism linked to the integrin alphaMbeta2 binding motif. J Clin Invest. 2007;117:3224-35.

19. Salvi R, Peclat V, So A, Busso N. Enhanced expression of genes involved in coagulation and fibrinolysis in murine arthritis. Arthritis Res. 2000;2:504-12.

20. Jacobsen S, Niewold TA, Halling-Thomsen M, Nanni S, Olsen E, Lindegaard $C$, et al. Serum amyloid $A$ isoforms in serum and synovial fluid in horses with lipopolysaccharide-induced arthritis. Vet Immunol Immunopathol. 2006;110:325-30.

21. Kitamoto Y, Nakamura E, Kudo S, Tokunaga H, Murakami E, Noguchi K, et al. Thrombin in synovial fluid as a marker of synovial inflammation: a definite measurement by ELISA and correlation with VEGF. Clin Chim Acta. 2008;398:159-60.

22. Russell FA, McDougall JJ. Proteinase activated receptor (PAR) involvement in mediating arthritis pain and inflammation. Inflamm Res. 2009;58:119-26.
23. Alturfan AA, Eralp L, Emekli N. Investigation of inflammatory and hemostatic parameters in female patients undergoing total knee arthroplasty surgery. Inflammation. 2008;31:414-21.

24. Liu XF, Piela-Smith TH. Fibrin(ogen)-induced expression of ICAM-1 and chemokines in human synovial fibroblasts. J Immunol. 2000;165:5255-61.

25. Masamune A, Kikuta K, Watanabe T, Satoh K, Hirota M, Hamada S, et al. Fibrinogen induces cytokine and collagen production in pancreatic stellate cells. Gut. 2009;58:550-9.

26. Sanchez-Pernaute O, Lopez-Armada MJ, Calvo E, Diez-Ortega I, Largo R, Egido J, et al. Fibrin generated in the synovial fluid activates intimal cells from their apical surface: a sequential morphological study in antigen-induced arthritis. Rheumatology (Oxford). 2003;42:19-25.

27. Ribera T, Rios J, Prades M, Monreal L, Delgado MA: Synovial fibrinolysis activity in horses with inflammatory joint/tendon sheath disease. Annual Congress of the European College of Veterinary Surgery (ECVS), Helsinki, Finland. July 2010

28. Ribera T, Monreal L, Delgado MA, Rios J, Prades M. Synovial fluid d-dimer concentration in horses with osteochondritis dissecans and osteoarthritis. Vet Comp Orthop Traumatol. 2013;26:54-60.

29. Haerdi-Landerer MC, Steiner A, Suter MM. Primary bovine synoviocyte cultures: A useful tool for in vitro drug testing? Vet J. 2011;188:58-63.

30. Upragarin N, van Asten AJAM, Tooten PCJ, Landman WJM, Gruys E. Serum amyloid A production by chicken fibroblast-like synoviocytes. Vet Immuno Immunopathol. 2005;106:39-51.

31. Santangelo KS, Johnson AL, Ruppert AS, Bertone AL. Effects of hyaluronan treatment on lipopolysaccharide-challenged fibroblast-like synovial cells. Arthritis Res Ther. 2007;9:R1.

32. Busso N, Peclat V, So A, Sappino AP. Plasminogen activation in synovial tissues: differences between normal, osteoarthritis, and rheumatoid arthritis joints. Ann Rheum Dis. 1997;56:550-7.

33. Esmon $\mathrm{CT}$. The impact of the inflammatory response on coagulation. Thromb Res. 2004;114:321-7.

34. Frisbie DD, Al-Sobayil F, Billinghurst RC, Kawcak CE, Mcllwraith CW. Changes in synovial fluid and serum biomarkers with exercise and early osteoarthritis in horses. Osteoarthritis Cartilage. 2008;16:1196-204.

35. van den Boom R, van der Harst MR, Brommer H, Brama PA, Barneveld A, van Weeren PR, et al. Relationship between synovial fluid levels of glycosaminoglycans, hydroxyproline and general MMP activity and the presence and severity of articular cartilage change on the proximal articular surface of P1. Equine Vet J. 2005;37:19-25.

36. Ribera T, Monreal L, Armengou L, Rios J, Prades M. Synovial fluid d-dimer concentration in foals with septic joint disease. J Vet Intern Med. 2011;25:1113-7.

37. Davalos $D$, Akassoglou K. Fibrinogen as a key regulator of inflammation in disease. Semin Immunopathol. 2012;34:43-62.

38. Hoppe B, Dorner T. Coagulation and the fibrin network in rheumatic disease: a role beyond haemostasis. Nat Rev Rheumatol. 2012;8:738-46.

39. Ogura N, Satoh K, Akutsu M, Tobe M, Kuyama K, Kuboyama N, et al. MCP-1 production in temporomandibular joint inflammation. J Dent Res. 2010;89:1117-22.

40. Ovlisen $\mathrm{K}$, Kristensen AT, Jensen AL, Tranholm M. IL-1 beta, IL-6, KC and MCP-1 are elevated in synovial fluid from haemophilic mice with experimentally induced haemarthrosis. Haemophilia. 2009;15:802-10.

41. Villiger PM, Terkeltaub R, Lotz M. Production of monocyte chemoattractant protein-1 by inflamed synovial tissue and cultured synoviocytes. J Immunol. 1992;149:722-7.

42. Harigai M, Hara M, Yoshimura T, Leonard EJ, Inoue K, Kashiwazaki S. Monocyte chemoattractant protein-1 (MCP-1) in inflammatory joint diseases and its involvement in the cytokine network of rheumatoid synovium. Clin Immunol Immunop. 1993;69:83-91.

43. Colotta F, Sciacca FL, Sironi M, Luini W, Rabiet MJ, Mantovani A. Expression of monocyte chemotactic protein-1 by monocytes and endothelial-cells exposed to thrombin. Am J Pathol. 1994;144:975-85.

44. Harley SL, Powell JT. Fibrinogen up-regulates the expression of monocyte chemoattractant protein 1 in human saphenous vein endothelial cells. Biochem J. 1999;341:739-44.

45. Seeger FH, Blessing E, Gu L, Bornhold R, Denger S, Kreuzer J. Fibrinogen induces chemotactic activity in endothelial cells. Acta Physiol Scand. 2002;176:109-15.

46. Barton $\mathrm{MH}$, Collatos C, Moore JN. Endotoxin induced expression of tumour necrosis factor, tissue factor and plasminogen activator inhibitor activity by peritoneal macrophages. Equine Vet J. 1996;28:382-9. 
47. Hoffman M, Monroe DM. A cell-based model of hemostasis. Thromb Haemost. 2001;85:958-65.

48. Busso N, Hamilton JA. Extravascular coagulation and the plasminogen activator/ plasmin system in rheumatoid arthritis. Arthritis Rheum. 2002;46:2268-79.

49. Bokarewa MI, Morrissey JH, Tarkowski A. Tissue factor as a proinflammatory agent. Arthritis Res. 2002;4:190-5.

50. Nonaka T, Kikuchi H, Ikeda T, Okamoto Y, Hamanishi C, Tanaka S. Hyaluronic acid inhibits the expression of U-PA, PAI-1, and u-PAR in human synovial fibroblasts of osteoarthritis and rheumatoid arthritis. J Rheumatol. 2000:27:997-1004

51. Alpay Z, Saed GM, Diamond MP. Postoperative adhesions: from formation to prevention. Semin Reprod Med. 2008;26:313-21.

52. Levi M, van der Poll T. Two-way interactions between inflammation and coagulation. Trends Cardiovasc Med. 2005;15:254-9.

53. Yang $Y H$, Hall $P$, Little CB, Fosang AJ, Milenkovski G, Santos L, et al. Reduction of arthritis severity in protease-activated receptor-deficient mice. Arthritis Rheum. 2005;52:1325-32.

54. Furuhashi I, Abe K, Sato T, Inoue H. Thrombin-stimulated proliferation of cultured human synovial fibroblasts through proteolytic activation of proteinase-activated receptor-1. J Pharmacol Sci. 2008;108:104-11.

55. Hirano F, Kobayashi A, Hirano Y, Nomura Y, Fukawa E, Makino I. Thrombininduced expression of RANTES MRNA through protease activated receptor-1 in human synovial fibroblasts. Ann Rheum Dis. 2002;61:834-7.

56. Lang R, Song PI, Legat FJ, Lavker RM, Harten B, Kalden H, et al. Human corneal epithelial cells express functional PAR-1 and PAR-2. Invest Ophthalmol Vis Sci. 2003;44:99-105.

57. Mbebi C, Rohn T, Doyennette MA, Chevessier F, Jandrot-Perrus M, Hantai D, et al. Thrombin receptor induction by injury-related factors in human skeletal muscle cells. Exp Cell Res. 2001;263:77-87.

58. Zhao AP, Dawson H, Urban JF, Finkelman FD, Shea-Donohue T. Up-regulation of PAR-1 and PAR-2 expression contributes to nematode-induced hypercontractility of murine intestinal smooth muscle. Gastroenterol. 2003;124:A89-9.

59. Ellis CA, Tiruppathi C, Sandoval R, Niles WD, Malik AB. Time course of recovery of endothelial cell surface thrombin receptor (PAR-1) expression. Am J Physiol. 1999;276:C38-45

60. Pompili E, Fabrizi C, Fumagalli L. PAR-1 upregulation by trimethyltin and lipopolysaccharide in cultured rat astrocytes. Int J Mol Med. 2006;18:33-9.

61. Rohatgi T, Henrich-Noack P, Sedehizade F, Goertler M, Wallesch CW, Reymann $K G$, et al. Transient focal ischemia in rat brain differentially regulates mRNA expression of protease-activated receptors 1 to 4. J Neurosci Res. 2004;75:273-9.

62. Yan W, Tiruppathi C, Qiao R, Lum H, Malik AB. Tumor necrosis factor decreases thrombin receptor expression in endothelial cells. J Cell Physiol. 1996;166:561-7.

63. Yoo SA, Kwok SK, Kim WU. Proinflammatory role of vascular endothelial growth factor in the pathogenesis of rheumatoid arthritis: prospects for therapeutic intervention. Med Inflam. 2008;2008:129873.

64. Lee SS, Joo YS, Kim WU, Min DJ, Min JK, Park SH, et al. Vascular endothelia growth factor levels in the serum and synovial fluid of patients with rheumatoid arthritis. Clin Exp Rheumatol. 2001;19:321-4.

65. Ludin A, Sela JJ, Schroeder A, Samuni Y, Nitzan DW, Amir G. Injection of vascular endothelial growth factor into knee joints induces osteoarthritis in mice. Osteoarthritis Cartilage. 2013;21:491-7.

66. Jansen $\mathrm{H}$, Meffert $\mathrm{RH}$, Birkenfeld F, Petersen W, Pufe T. Detection of vascular endothelial growth factor (VEGF) in moderate osteoarthritis in a rabbit model. Ann Anat. 2012;194:452-6.

67. Kim CO, Huh AJ, Kim MS, Chin BS, Han SH, Choi SH, et al. LPS-induced vascular endothelial growth factor expression in rat lung pericytes. Shock. 2008;30:92-7.

68. Shiose S, Hata Y, Noda Y, Sassa Y, Takeda A, Yoshikawa H, et al. Fibrinogen stimulates in vitro angiogenesis by choroidal endothelial cells via autocrine VEGF. Graef Arch Clin Exp. 2004;242:777-83.

69. Huang YQ, Li JJ, Hu L, Lee M, Karpatkin S. Thrombin induces increased expression and secretion of VEGF from human FS4 fibroblasts, DU145 prostate cells and CHRF megakaryocytes. Tromb Haemost. 2001;86:1094-8.

70. Guo F, Liu J, Wang C, Liu N, Lu P. Fibrinogen, fibrin, and FDP induce C-reactive protein generation in rat vascular smooth muscle cells: pro-inflammatory effect on atherosclerosis. Biochem Bioph Res Co. 2009;390:942-6.

71. Lu PP, Liu JT, Liu N, Guo F, Ji YY, Pang XM. Pro-inflammatory effect of fibrinogen and FDP on vascular smooth muscle cells by IL-6, TNF-alpha and iNOS. Life Sci. 2011:88:839-45.
72. Haneda S, Nagaoka K, Nambo Y, Kikuchi M, Nakano Y, Matsui M, et al. Interleukin-1 receptor antagonist expression in the equine endometrium during the peri-implantation period. Domest Anim Endocrin. 2009;36:209-18.

73. Deschene K, Celeste C, Boerboom D, Theoret CL. Constitutive expression of hypoxia-inducible factor-1 alpha in keratinocytes during the repair of skin wounds in horses. Wound Repair Regen. 2011;19:250-9.

74. lqbal J, Bird JL, Hollander AP, Bayliss MT. Effect of matrix depleting agents on the expression of chondrocyte metabolism by equine chondrocytes. Res Vet Sci. 2004;77:249-56.

75. Tellmann GG. O: LightCycler 480 Real-Time PCR system: Innovative solutions for relative quantification. Biochemica. 2006;4:16-7.

76. R: A language and environment for statistical computing [http://www.R-project.org]

\section{Submit your next manuscript to BioMed Central and take full advantage of:}

- Convenient online submission

- Thorough peer review

- No space constraints or color figure charges

- Immediate publication on acceptance

- Inclusion in PubMed, CAS, Scopus and Google Scholar

- Research which is freely available for redistribution 